University of Rhode Island

DigitalCommons@URI

Cancer Prevention Research Center Faculty

Publications

Cancer Prevention Research Center

1995

\title{
Contraceptive and Condom Use Adoption and Maintenance: A Stage Paradigm Approach
}

Diane M. Grimley

University of Rhode Island

James O. Prochaska

University of Rhode Island, joprochaska@uri.edu

Wayne F. Velicer

University of Rhode Island, VELICER@URI.EDU

Follow this and additional works at: https://digitalcommons.uri.edu/cprc_facpubs

Terms of Use

All rights reserved under copyright.

\section{Citation/Publisher Attribution}

Grimley, D. M., Prochaska, J. O., \& Velicer, W. F. (1995). Contraceptive and Condom Use Adoption and Maintenance: A Stage Paradigm Approach. Health Education and Behavior, 22(1), 20-35. doi: 10.1177/ 109019819502200104

Available at: http://dx.doi.org/10.1177/109019819502200104

This Article is brought to you for free and open access by the Cancer Prevention Research Center at DigitalCommons@URI. It has been accepted for inclusion in Cancer Prevention Research Center Faculty Publications by an authorized administrator of DigitalCommons@URI. For more information, please contact digitalcommons-group@uri.edu. 


\title{
Contraceptive and Condom Use Adoption and Maintenance: A Stage Paradigm Approach
}

\author{
Diane M. Grimley, $\mathrm{PhD}$ \\ James O. Prochaska, $\mathrm{PhD}$ \\ Wayne F. Velicer, $\mathrm{PhD}$ \\ Gabrielle E. Prochaska, RA
}

\begin{abstract}
The Transtheoretical Model of Behavior Change was examined for its applicability to contraceptive and condom use adoption and maintenance using $N=248$ heterosexually active college-age men and women. The model posits that individuals do not go directly from old behaviors to new behaviors, but progress through a sequence of stages: precontemplation, contemplation, preparation, action, and maintenance. The stages of change offer a temporal dimension that provides information regarding when a particular shift in attitudes, intentions, and behavior may occur. The model also postulates a set of constructs that act as sensitive intervening or outcome variables - the pros and cons of change and self-efficacy. The results demonstrated that individuals were furthest along in the stages of change for general contraceptive use, followed closely by condom use with other (e.g., casual) partners, and then condom use with main partners. Although no sex differences were found for the stages for the three separate contraceptive behaviors, males and females differed on the pros and cons and levels of self-efficacy when engaging in intercourse with the two types of partners. MANOVA/ANOVA results indicated that the relationship between stages and other constructs follows predicted patterns suggesting that the transtheoretical model may provide a useful framework or paradigm for understanding contraceptive and condom use behavior.
\end{abstract}

\section{INTRODUCTION}

The inconsistent use of contraceptives and condoms is a complex problem and an obvious contributor to the current high rates of unplanned pregnancies and sexually transmitted diseases (STDs). Each year in the United States, nearly 1 million adolescents become pregnant. ${ }^{1}$ The United States has one of the highest abortion rates and one of the highest rates of unintended births in the Western, developed world. ${ }^{2}$ In addition, an estimated 12 million cases of STDs occur each year in the United States with serious health consequences for thousands of children and adults. ${ }^{3}$ Moreover, sexually active individuals today have to deal with the threat of infection from the human immunodefi-

All authors are at the Cancer Prevention Research Center, University of Rhode Island.

Address reprint requests to Diane M. Grimley, $\mathrm{PhD}$, Cancer Prevention Research Center, University of Rhode Island, Flagg Rd., Kingston, RI 02881-0808. Telephone: (401) 792-2830; e-mail: gva101@uriacc.uri.edu.

This article was supported in part by grants CA27821 and CA50087 from the National Cancer Institute and CSA-92-109 from the Centers for Disease Control and Prevention. 
ciency virus (HIV), which can lead to the acquired immunodeficiency syndrome (AIDS). This study applies the Transtheoretical Model of Behavior Change $\mathrm{e}^{4-6}$ to contraceptive and condom use in order to examine the model's applicability to these two related health behaviors.

\section{APPLICATION OF THE TRANSTHEORETICAL MODEL TO CONTRACEPTIVE AND CONDOM USE}

The limitations of many existing behavior change programs highlight the need for a new behavior change technology. ${ }^{7}$ An alternative research paradigm is the Transtheoretical Model of Behavior Change. The model provides a useful framework for understanding how individuals intentionally change their behaviors, with or without professional intervention. The model defines change as a gradual, continuous, and dynamic process. It holds that individuals do not go directly from old behaviors to new behaviors (e.g., not using condoms to using condoms always), but progress through a sequence of stages: precontemplation, contemplation, preparation, action, and maintenance. Similar concepts have been discussed by others. ${ }^{8,9}$ The stages of change offer a temporal dimension that provides information regarding when a particular shift in attitudes, intentions, and behavior may occur. Progression through the stages is often not linear, because many individuals regress and cycle back through the earlier stages. Individuals may recycle through the stages several times before they succeed in their efforts to change.

The model has been applied to a broad range of health behaviors. ${ }^{10}$ In the area of sexual behavior, the model has been theoretically applied to HIV prevention, " applied empirically to safer sex practices in general, ${ }^{12}$ and applied specifically to contraceptive and condom use adoption. ${ }^{13-17}$ The model's intervention strategy is to provide behavior change programs that match the stage of change people are in, rather than expect individuals to match action-oriented programs. In addition to assessing an individual's intention to change (i.e., stage of change), the model examines the perceived payoff for the individual for adopting and continuing healthy behaviors (i.e., decisional balance or the pros and cons of making a healthy behavior change $)^{10,18}$ and examines the person's ability to perform the behavior(s) necessary that will lead to, and then maintain, successful behavior change, or self-efficacy, ${ }^{19,20}$ which Bandura ${ }^{21,22}$ considers the most important construct in social learning theory. A fourth construct of the model, the processes of change, ${ }^{23.24}$ has been successfully applied to contraceptive and condom use behavior and is described in detail elsewhere. ${ }^{15,16}$

What is unique to sexual behavior as compared to other behaviors examined using the transtheoretical model is the dyadic relation that exists. As with most models of behavior change, the transtheoretical model's focus is on individual change. Yet the model takes into account the attitudes and behaviors of a given partner that may be influential factors regarding contraceptive choice, particularly condom use. For example, a number of studies have demonstrated the need to model condom use separately for different types of partners. ${ }^{16,17,25,26}$ The current study employed separate assessments for condom use with main and secondary partners. Other variables from the model were developed so as to capture interpersonal and social/situational aspects that may affect willingness or ability to use condoms. Finally, the model has been expanded to enhance its value in the STD/HIV context by including the construct of condom use assertiveness described in detail elsewhere. ${ }^{14}$ 


\section{Research Hypotheses}

This study investigated the applicability of three constructs from the transtheoretical model-the stages of change, decisional balance, and self-efficacy-to the important issues of contraceptive and condom use adoption and maintenance. The major aim was to classify individuals into the five stages of change for contraceptive and condom use. Earlier work based on the model ${ }^{11}$ stressed the importance of an appropriate behavioral criterion for the preparation stage of contraceptive and condom use adoption. The present investigation attempted to further refine recent efforts in this direction ${ }^{14}$ by examining the utility of "intention to change in the next 30 days" combined with the behavioral criterion of currently using birth control and/or condoms "almost every time."

In addition, recent studies ${ }^{12,27,28}$ have reported sex differences for general condom use without specifying partner type. It was hypothesized that a more sensitive assessment of condom use may result from an examination of condom use behavior with main versus other partners, potentially leading to a better understanding of men's and women's attitudes and behaviors regarding condom use.

Moreover, based on previous empirical findings with a broad range of health behaviors, ${ }^{8}$ it was hypothesized that individuals in the precontemplation stage would evaluate the negative aspects of using contraceptives and/or condoms as being higher than the pros of their use and that the relation between the pros and cons would be reversed for individuals in the maintenance stage. Finally, individuals were expected to report the lowest levels of perceived self-efficacy in the precontemplation stage and confidence levels were expected to rise moderately across the stages of change for the separate contraceptive behaviors. ${ }^{16,17}$

\section{METHOD}

\section{Procedure}

Individuals were recruited from psychology classes at a northeastern university. Each participant was asked to complete an anonymous questionnaire in a single-occasion, cross-sectional design. Participants were given partial credit toward their course requirements by their individual instructors for completing the survey. Data were collected in 1993.

Approximately 550 students were offered the opportunity to participate in the study and 303 volunteered to be assessed. Only data from single, heterosexually active individuals were analyzed, leaving a final sample size of $N=248$. The majority of the sample were female $(62.5 \%)$. The mean age was 18.88 and ranged from 18 to 26 . Seventy percent were Catholic and $94.7 \%$ were Caucasian.

\section{Measures}

The measures were embedded in a longer questionnaire. Five types of measures were used in the present study: basic demographics; a traditional sexual history assessment; stages of change algorithms for general contraceptive use, condom use with main partner, and condom use with other (e.g., casual) partner(s); decisional balance measures; and self-efficacy measures for the three contraceptive behaviors. 


\section{Stages of Change Algorithms}

To assess an individual's readiness to adopt and maintain birth control and condom use, three separate four- or five-item staging algorithms were used for (a) general contraceptive use (four items), (b) condom use with a main partner (five items), and (c) condom use with casual partners (five items).

The rationale for using a general measure for contraceptive use was based on previous findings, ${ }^{16,29-30}$ which demonstrated empirically that the measure could be employed when assessing specific methods of birth control such as the pill and Norplant, yielding comparable and valid results. The validity of separate algorithms to assess condom use behavior for vaginal sex with different partner types has been established and is described in detail elsewhere. ${ }^{16-17,29}$ Sample items employed to assess condom use with a main partner are given in Table 1.

The following classification scheme results from the assessment of condom use for vaginal intercourse with individuals reporting a primary partner:

1. Precontemplation includes individuals who were not using condoms with their main partners and had no intention to start doing so every time in the next 6 months.

2. Contemplation includes persons who are not currently using condoms with their main partners, but intend to start doing so every time in the next 6 months.

3. Preparation consists of individuals who intend to start using condoms every time within the next month and are currently using condoms almost every time with their main partner.

4. Action includes individuals who have been using condoms every time for less than 6 months.

5. Maintenance includes individuals who have been using condoms with their main partners every time for more than 6 months.

\section{Decisional Balance (Pros and Cons)}

Three 10-item measures for the pros and cons of using contraceptives and condoms ( 5 pros and 5 cons) were employed. Item content for the pros of each measure involved the advantages (pros) of contraceptive use, such as protection from pregnancy and/or diseases; perceived effectiveness; and ease of use. The content covered by the disadvantages (cons) of contraceptive use includes such potential areas of concern as physical side effects, partner's reaction to contraceptive use, and less perceived sexual enjoyment. An item for the pros of condom use, for example, is "I would feel safer from diseases," whereas a cons item is "I would have to rely on my partner's cooperation." Each participant was asked to rate how important each statement is to his or her decision whether or not to use contraceptives. A 5-point Likert-type response option was used, ranging from $1=$ not important to $5=$ extremely important. Internal consistency (coefficient alpha) ranged from .82 to .93 for the three pros scales and .81 to .87 for the three cons scales in a preliminary investigation involving a high-risk sample. ${ }^{16.29}$

\section{Self-Efficacy}

Three five-item measures were used to examine an individual's perceived ability to use contraceptives and for using condoms with main and casual partners. Participants 
Table 1. Algorithm for Condom Use with a MAIN Partner (VAGINAL SEX)

Q.1. Do you have a main or steady sex partner of the opposite sex?

1) Yes

2) No (Skip to assessment of other partners)

Q.2. When you have vaginal sex with your main partner, how often do you use a condom?

1) Every time (Go on to Q.3)

2) Almost every time (Skip to Q.4)

3) Sometimes (Skip to Q.4)

4) Almost never (Skip to Q.4)

5) Never (Skip to Q.4)

Q.3. How long have you been using a condom every time you have vaginal sex with your main partner?

1) 30 days or less

2) More than 30 days-less than 6 months

3) 6 months or more

(Skip to assessment of other partners)

Q.4. Do you intend to start using condoms every time you have vaginal sex with your main partner in the next 6 months?
1) No (Skip to "Other" partners)
2) Yes (Go on to Q.5)

Q.5. Do you intend to start using condoms every time you have vaginal sex with your main partner in the next 30 days?
1) No
2) Yes

(Go on to "Other" partners)

NOTE: Scoring for staging algorithm is available upon request.

were asked to rate how confident they would be using contraceptives, in general, and condoms with the two types of partners in specific sexual situations. Items were written in such a way as to assess the degree of situational pull that might exist (e.g., using alcohol or drugs) that could induce an individual to have intercourse without the use of contraceptives. An example item is "How confident are you that you would use a condom when you think your partner might get angry?" Each of the items was rated on a 5-point Likert-type scale ranging from $1=$ not at all confident to $5=$ very confident. Reliability coefficients for the three self-efficacy measures ranged from .84 to .88 in a preliminary study on a high-risk sample. ${ }^{16,29}$

\section{RESULTS}

\section{Brief Sexual History}

Over one half of the sample $(58.7 \%)$ had engaged in vaginal intercourse by age 16 , with $63.3 \%$ reporting that a condom was used during this sexual debut. More than half the sample $(54.4 \%)$ had three or more sex partners since becoming sexually active, with men reporting significantly more partners than women $(p=.009)$. Sixty-eight percent currently had a main partner and $22.4 \%$ of these same individuals reported having vaginal intercourse with someone else during their relationship with their current primary partner. Just over one third $(39.8 \%)$ reported using condoms to prevent both pregnancy and disease with their main partner, as compared with three fourths $(75.3 \%)$ of those having vaginal intercourse with other partners. Regarding the use of specific methods by 
individuals and their partners to prevent pregnancy: $64.2 \%$ used condoms, but not consistently; $27.0 \%$ used the pill; $1 \%$ used the sponge; and $7.8 \%$ reported using nothing. No one in the current sample, or their partners, was using the IUD, the diaphragm, or Norplant.

\section{Readiness for Change}

Out of 248 heterosexual young adults, $n=244$ were successfully staged for general contraceptive use. Of those individuals with a main partner $(n=166), 134$ were able to be staged for condom use and 78 (out of $n=80$ ) individuals reporting a casual partner were staged for consistent condom use.

Table 2 presents stage distributions for the three contraceptive behaviors. The results indicate that half the sample (50.6\%) were not using a method of birth control every time; $51.4 \%$ were not using condoms every time to prevent pregnancy and/or STDs when engaging in vaginal intercourse with casual partners; and $70.4 \%$ were not using condoms every time with their main partners. No sex differences were found for the staging distributions for the three target behaviors.

\section{Decisional Balance}

The overall mean score indicated that the highest pro for both general contraceptive use and for condom use with a main partner was protection from pregnancy. For using condoms with casual partners, the highest reported pro was protection from diseases. These findings suggest that individuals in this sample may perceive themselves at risk for becoming pregnant with a main partner, but see themselves at greater risk for contracting diseases when engaging in vaginal intercourse with casual partners. Coefficient alphas for the pros ranged from .75 to .78 with the current sample.

The highest con for general contraceptive use was that it can make sex feel unnatural. Relying on a partner's cooperation was found to be the strongest con for using condoms with both types of partners. These findings for the cons are consistent with earlier observations ${ }^{16}$ and point out that having to elicit a partner's compliance for using condoms serves as a potential barrier to their use.

Women had significantly higher mean pro scores for general contraceptive use (females $M=4.64$ vs. males $M=4.23, p=.0001$ ) and for condom use with a main partner (females $M=4.53$ vs. males $M 4.25, p=.015$ ). Men reported higher perceived cons for general contraceptive use (males $M=2.18$ vs. females $M=1.80, p=.001$ ) and for using condoms with a main partner (males $M=2.69$ vs. females $M=2.29, p=.008$ ). No significant sex differences were detected for the pros and cons for using condoms with a casual partner. The item means scores by gender for the pros and cons of contraceptive and condom use are given in Table 3 .

\section{Pros and Cons Across the Five Stages of Change}

To provide a standard metric, the pros and cons for all individuals were converted from raw scores to standard scores and then to $T$-scores $(M=50, S D=10)$. Table 4 contains the $T$-score means and standard deviations for each decisional balance measure by stage 
Table 2. Percentages of Individuals in the Five Stages of Change for Contraceptive and Condom Use

\begin{tabular}{|c|c|c|c|c|c|c|c|}
\hline \multirow[b]{2}{*}{ Method } & \multicolumn{2}{|c|}{$N$} & \multicolumn{5}{|c|}{ Stage of Change } \\
\hline & Males & Females & PC & $\mathrm{C}$ & $\mathbf{P}$ & A & $\mathbf{M}$ \\
\hline General contraceptives & 90 & 154 & 6.1 & 12.7 & 31.8 & 11.8 & 37.6 \\
\hline Condom-other & 34 & 44 & 6.4 & 19.2 & 24.4 & 20.5 & 29.5 \\
\hline Condom-main & 41 & 93 & 23.0 & 15.6 & 32.6 & 12.6 & 16.3 \\
\hline
\end{tabular}

NOTE: $\mathrm{PC}=$ precontemplation, $\mathrm{C}=$ contemplation, $\mathrm{P}=$ preparation, $\mathrm{A}=$ action, and $\mathrm{M}=$ maintenance.

of change. Consistent with Prochaska's "strong and weak principles" of behavior change, the pros of contraceptive and condom use increased approximately 1 standard deviation between the precontemplation and action stages of adoption for the three contraceptive behaviors, whereas the cons decreased about half of a standard deviation for two out of three behaviors.

Three multivariate analyses of variance (MANOVAs) were performed using individuals with complete data on staging and decisional balance measures only. Significant differences between the pros and cons across the stages of change were detected: general contraceptive use, $F(8,316)=2.87, p=.004 ;$ condom-main, $F(8,230)=6.43, p=.0001$; and condom-other, $F(8,134)=2.18, p=.033$. Follow-up analysis of variance (ANOVA) detected significant differences for the pros of using contraceptives and condoms: general contraceptive use, $F(4,160)=5.12, p=.0007$; condom-main, $F(4,118)=12.21, p=$ .0001 ; and condom-other, $F(4,70)=4.68, p=.002$. Tukey test results indicated that there were significantly lower scores for individuals in the precontemplation stage for general contraceptive use as compared to the action and maintenance stages; precontemplation scores were significantly lower than the other four stages of change for condom use with a main partner; and individuals in the precontemplation stage had lower scores than those in the preparation, action, and maintenance stages for using condoms with casual partners. No significant differences were found for the cons of using contraceptives and condoms. This lack of difference found for the cons across the stages is consistent with earlier studies ${ }^{13,16,17}$ and suggests that some of the negative aspects of using contraceptives and condoms (e.g., hassles) may exist no matter what stage of change an individual may be in.

Graphic representation of the pros and cons across the stages are presented in Figure 1. Overall, the cons for using contraceptives and condoms are higher than the pros for individuals in the precontemplation stage. The opposite is true for those in the action and maintenance stages of change. The crossover of the pros and cons occurs before or during the preparation stage. These findings are consistent with those found by Prochaska et al., ${ }^{10}$ with a broad range of behaviors demonstrating that the crossover of the pros and cons occurs some time before individuals take action to modify problem behaviors.

\section{Self-Efficacy}

Overall item means indicated that lower levels of self-efficacy were reported for general birth control if individuals were using alcohol or other drugs. Substance use might 
Table 3. Item Means by Gender for the Pros and Cons of Contraceptive and Condom Use

\begin{tabular}{lll}
\hline Method Item & Females $M$ & Males $M$ \\
\hline General contraceptive use & $n=155$ & $n=93$ \\
Pros & & \\
1. I would be safer from pregnancy & 4.85 & 4.61 \\
2. I would feel more responsible & 4.38 & 3.89 \\
3. I would not have to deal with the results of a pregnancy & 4.77 & 4.28 \\
4. I would be free to have sex without worrying about & & \\
getting pregnant & 4.52 & 4.02 \\
5. My partner would not have to worry about a pregnancy & & \\
occurring & 4.76 & 4.35 \\
Cons & & \\
1. Birth control methods can make sex feel unnatural & 2.26 & 2.60 \\
2. It would be too much trouble & 1.55 & 1.93 \\
3. It would cost too much & 1.64 & 1.77 \\
4. It is against my beliefs & 1.57 & 1.79 \\
5. Sex would be less exciting & 2.01 & 2.69 \\
Condom-main & $n=116$ & $n=54$ \\
Pros & & \\
1. I would be safer from disease & 4.62 & 4.19 \\
2. I would feel more responsible & 4.26 & 3.96 \\
3. It protects my partner as well as myself & 4.58 & 4.32 \\
4. I would be safer from pregnancy & 4.80 & 4.45 \\
5. It is easily available & 4.37 & 4.06 \\
Cons & & \\
1. It can make sex feel unnatural & 2.40 & 2.85 \\
2. It would be too much trouble & 2.05 & 2.31 \\
3. My partner would be angry & 1.66 & 2.74 \\
4. I would have to rely on my partner's cooperation & 3.42 & 3.39 \\
5. My partner would think that I do not trust him/her & 1.96 & 2.40 \\
Condom-other & $n=50$ & $n=42$ \\
Pros & & \\
1. I would be safer from diseases & 4.88 & 4.71 \\
2. I would feel more responsible & 4.41 & 4.14 \\
3. It protects my partner as well as myself & 4.71 & 4.29 \\
4. I would be safer from pregnancy & 4.82 & 4.42 \\
5. It is easily available & 4.39 & 4.17 \\
Cons & & \\
1. It makes sex feel unnatural & 2.16 & 2.52 \\
2. It would be too much trouble & 2.34 \\
3. My partner would be upset & 2.90 \\
4. My partner would think that I "play around" & & \\
5. I would have to rely on my partner's cooperation & & \\
\hline
\end{tabular}

NOTE: Scales range from 1 to 5 .

interfere with birth control use because the majority of the sample used condoms, although not consistently, for pregnancy prevention. Overall, individuals had more confidence for using condoms with other partners, as compared to steady partners ( $M=3.63$ vs. $M=$ $3.34, p=.04$ ). However, with both types of partners, lower self-efficacy for using condoms 
Table 4. T-Score Means and Standard Deviations of the Pros and Cons Across the Stages of General Contraceptive and Condom Use

\begin{tabular}{|c|c|c|c|c|c|c|}
\hline \multirow[b]{2}{*}{ Method } & & \multicolumn{5}{|c|}{ Stage of Change } \\
\hline & & $\mathrm{PC}$ & $\mathrm{C}$ & $P$ & A & $\mathbf{M}$ \\
\hline \multicolumn{7}{|c|}{ General contraceptive } \\
\hline & $M$ & 42.23 & 45.59 & 51.23 & 54.45 & 50.91 \\
\hline & $S D$ & 12.18 & 12.21 & 6.03 & 3.42 & 9.22 \\
\hline \multicolumn{7}{|l|}{ Cons } \\
\hline & $M$ & 52.68 & 53.98 & 51.00 & 47.19 & 48.92 \\
\hline & $S D$ & 9.55 & 8.40 & 9.88 & 9.87 & 10.96 \\
\hline \multicolumn{7}{|c|}{ Condom-main } \\
\hline \multicolumn{7}{|c|}{ Pros } \\
\hline & $M$ & 43.95 & 51.35 & 53.35 & 55.81 & 56.30 \\
\hline & $S D$ & 9.48 & 8.31 & 3.91 & 4.45 & 3.66 \\
\hline \multicolumn{7}{|l|}{ Cons } \\
\hline & $M$ & 52.62 & 53.41 & 50.24 & 46.96 & 45.43 \\
\hline & $S D$ & 9.85 & 10.80 & 8.38 & 13.83 & 9.56 \\
\hline \multicolumn{7}{|c|}{ Condom-other } \\
\hline \multicolumn{7}{|l|}{ Pros } \\
\hline & $M$ & 40.47 & 48.51 & 50.40 & 54.36 & 53.79 \\
\hline & $S D$ & 15.09 & 11.38 & 10.90 & 4.56 & 4.97 \\
\hline \multicolumn{7}{|l|}{ Cons } \\
\hline & $M$ & 50.58 & 49.83 & 48.41 & 50.45 & 49.80 \\
\hline & $S D$ & 12.43 & 9.33 & 8.25 & 9.43 & 12.60 \\
\hline
\end{tabular}

NOTE: $\mathrm{PC}=$ precontemplation, $\mathbf{C}=$ contemplation, $\mathrm{P}=$ preparation, $\mathrm{A}=$ action, and $\mathbf{M}=$ maintenance.

was reported when individuals or their partners were already using another method of birth control. Reliability coefficients ranged from .82 to .89 .

Sex differences for self-efficacy were revealed at the .05 level for two out of three contraceptive behaviors. Women reported higher levels of self-efficacy for contraceptive use in general (females, $M=3.69$ vs. males, $M=3.39$ ) and condom use with a casual partner (females, $M=3.80$ vs. males, $M=3.41$ ). No sex differences were observed for self-efficacy for condom use with a main partner. Item means by gender for self-efficacy for the three separate contraceptive behaviors are presented in Table 5 .

\section{Self-Efficacy Across the Stages of Change}

The self-efficacy raw scores were converted to $T$-scores $(M=50, S D=10)$. Table 6 contains the $T$-score means and standard deviations for each self-efficacy measure by stage of change. Three separate ANOVAs were performed using individuals with complete data on staging and self-efficacy measures. Significant mean differences were found across the stages for all three contraceptive behaviors: general contraceptive use, $F(4$, $158)=6.63, p=.0001$; condom-main, $F(4,116)=56.69, p=.0001$; and condom-other, $F(4,69)=10.01, p=.0001$. Follow-up Tukey tests indicated that there were significantly lower scores for individuals in the precontemplation stage for all methods. 


\section{Pros and Cons of General Contraceptive Use}
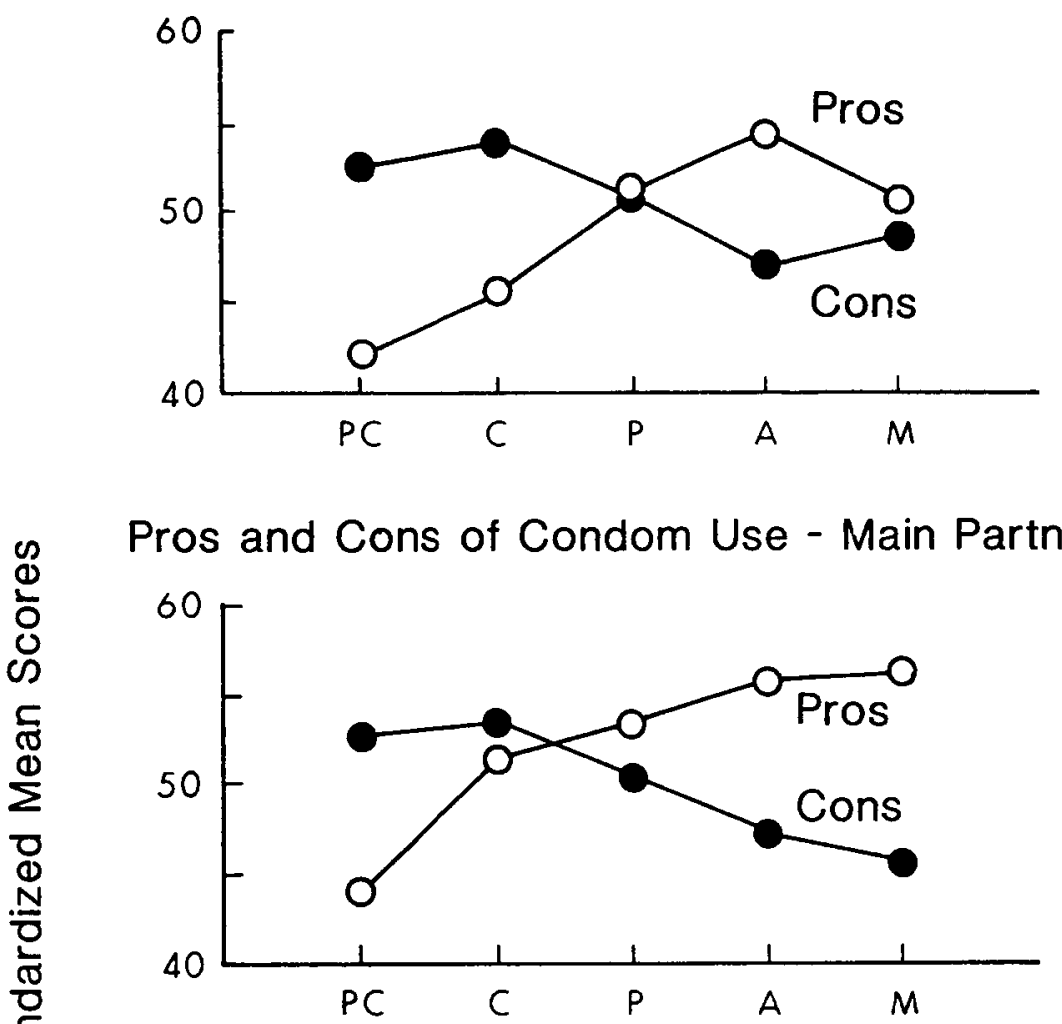

Pros and Cons of Condom Use - Other Partner(s)

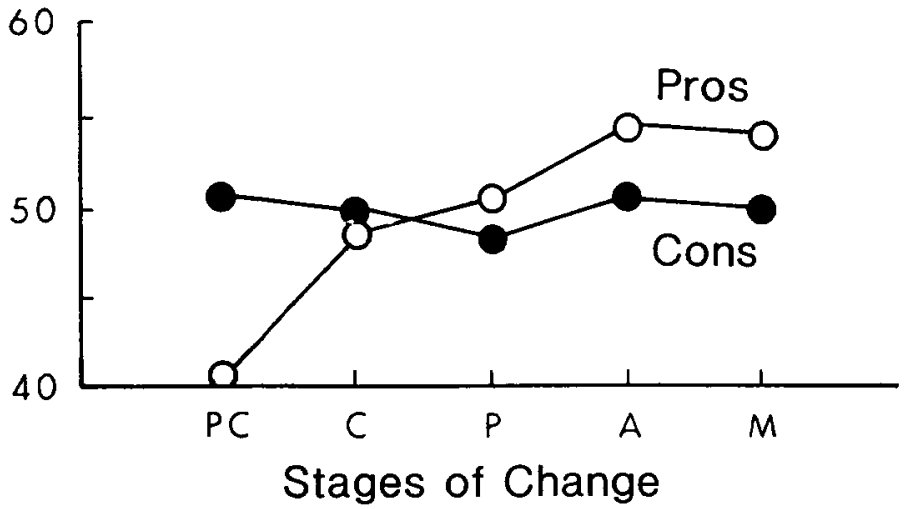

Figure 1. The pros and cons ( $T$-score means) of using contraceptives in general, condoms with a main partner, and condoms with someone other than a main partner by precontemplation (PC), contemplation (C), preparation $(\mathrm{P})$, action $(\mathrm{A})$, and maintenance $(\mathrm{M})$ stages of change. 
Table 5. Item Means by Gender for Self-Efficacy for Contraceptive and Condom Use

\begin{tabular}{lll}
\hline Method Item & Females $M$ & Males $M$ \\
\hline General contraceptive use & $n=155$ & $n=93$ \\
1. When a method of birth control is not right on hand & 3.62 & 3.18 \\
2. When you have been using alcohol or other drugs & 3.37 & 3.27 \\
3. When your partner gets upset about it & 3.93 & 3.80 \\
4. When you (or your partner) feel side effects & 3.66 & 3.41 \\
5. When it is too much trouble & 3.80 & 3.34 \\
Condom-main & $n=116$ & $n=53$ \\
1. When you have been using alcohol or other drugs & 3.22 & 3.25 \\
2. When you are sexually aroused & 3.48 & 3.46 \\
3. When you think that your partner might get angry & 3.79 & 3.65 \\
4. When you are already using another method of birth & & \\
control & 2.48 & 2.61 \\
5. When you want your partner to know you are committed & & \\
to your relationship & 3.70 & 3.77 \\
Condom-other & $n=49$ & $n=42$ \\
1. When you think the risk of disease is low & 4.06 & 3.74 \\
2. When you have been using alcohol or other drugs & 3.67 & 3.40 \\
3. When you cannot discuss condom use with a partner & 3.96 & 3.40 \\
4. When you think your partner might get upset & 3.96 & 3.50 \\
5. When you are already using another method of birth & & \\
$\quad$ control & 3.43 & 3.02 \\
\hline
\end{tabular}

NOTE: All scales range from 1 to 5 . Lower scores indicate lower confidence.

Table 6. T-Score Means and Standard Deviations for Self-Efficacy Across the Stages of General Contraceptive and Condom Use

\begin{tabular}{|c|c|c|c|c|c|c|}
\hline \multirow[b]{2}{*}{ Method } & & \multicolumn{5}{|c|}{ Stage of Change } \\
\hline & & PC & $\mathrm{C}$ & $P$ & A & $\mathbf{M}$ \\
\hline \multicolumn{7}{|c|}{ General contraceptive } \\
\hline & $M$ & 43.58 & 43.93 & 46.84 & 55.35 & 52.85 \\
\hline & $S D$ & 7.97 & 7.30 & 7.67 & 9.62 & 11.12 \\
\hline \multicolumn{7}{|c|}{ Condom-main } \\
\hline & $M$ & 40.19 & 49.27 & 56.01 & 57.88 & 60.00 \\
\hline & $S D$ & 7.56 & 4.00 & 4.98 & 5.60 & 3.81 \\
\hline \multicolumn{7}{|c|}{ Condom-other } \\
\hline & $M$ & 40.72 & 45.78 & 53.48 & 57.25 & 55.23 \\
\hline & $S D$ & 7.37 & 6.90 & 9.03 & 8.52 & 7.61 \\
\hline
\end{tabular}

NOTE: $\mathrm{PC}=$ precontemplation, $\mathrm{C}=$ contemplation, $\mathrm{P}=$ preparation, $\mathrm{A}=$ action, and $\mathrm{M}=$ maintenance.

Graphic representation of self-efficacy across the stages of general contraceptive and condom use with the two types of partners are presented in Figure 2. For all three behaviors, self-efficacy is the lowest in the precontemplation stage, starts to climb for those further along in the stages of change, and then peaks in the action or maintenance stage. 

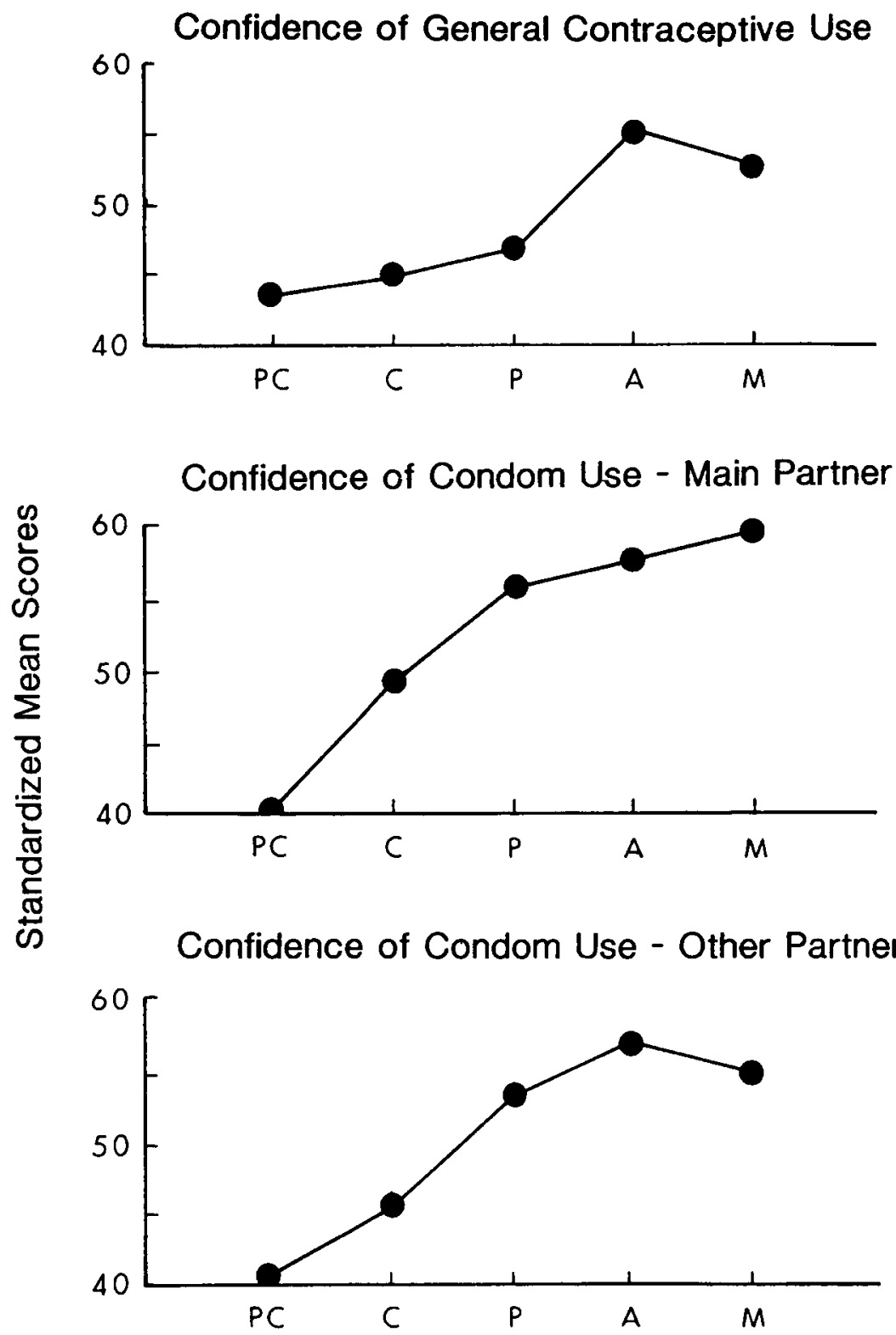

\section{Stages of Change}

Figure 2. Self-efficacy ( $T$-score means) for using contraceptives in general, for using condoms with a main partner, and for using condoms with someone other than a main partner by precontemplation (PC), contemplation (C), preparation $(\mathrm{P})$, action $(\mathrm{A})$, and maintenance $(\mathrm{M})$ stages of change.

\section{DISCUSSION}

The overall findings suggest that the measures for the three constructs from the transtheoretical model-the stages of change, decisional balance, and self-efficacy-hold 
promise for their application to college men and women in the area of contraceptive and condom use adoption and maintenance. Several interesting findings emerged. First, the behavioral criterion of using contraceptives and/or condoms almost every time adequately defined the preparation stage of readiness. Heterosexually active individuals were successfully classified into the five stages of change for contraceptive and condom use. Half of the sample were not using birth control consistently, half of the individuals having vaginal intercourse with secondary partners were not using condoms, and over two thirds were not using condoms every time they engaged in vaginal intercourse with their steady partners. These results support and extend previous findings ${ }^{16,17,29}$ and stress the need for health care providers to assess an individual's condom use behavior with different types of partners.

Second, consistent with previous studies, ${ }^{28}$ men and women did not differ on present contraceptive and condom use or on their intentions to use them in the future. Similar to other studies, women held more favorable attitudes toward the use of contraceptives in general and for using condoms with main partners. Conversely, men evaluated the negative aspects of their use as being higher. Yet, in contrast to other studies, no sex differences emerged for the pros and cons of condom use with casual partners, suggesting that men and women may share similar attitudes in such sexual situations. These sex differences across partner type are potentially important as well as informative. Therefore, recommendations for interventions that stress sex differences should also emphasize partner type.

Third, for all three contraceptive behaviors, individuals in the precontemplation stage of change were shown to evaluate the cons as higher than the pros of their use. The opposite was true for those in the maintenance stage. Consistent with earlier findings, ${ }^{10}$ the crossover of the pros and cons for the three contraceptive behaviors occurs before action takes place. Model-based research has shown that interventions have the potential to be effective if the pros of engaging in the healthy behavior are emphasized. ${ }^{10}$ In other words, movement from precontemplation to contemplation is a function of an increase in the perceived pros of using contraceptives and/or condoms. These findings suggest that the advantages of using contraceptives and condoms need to be made more salient for individuals. The current expensive media campaigns that focus on the negative aspects of unplanned pregnancy and infection from STDs might be more effective if public policy permitted them to stress the advantages and safety of contraceptives as well. ${ }^{32}$ Information channels such as sex education courses and public health messages may also need to be revised. ${ }^{33}$ Modification techniques should deal directly with the positive aspects of contraceptive and condom use for individuals who are in the precontemplation stage of readiness (e.g., "Using condoms tells your partners that you care about them"). Once a person has progressed to the contemplation stage and is at least thinking about using contraceptives and/or condoms, then interventions need to focus on decreasing the negative aspects (cons) of their use, which should lead to further progress from contemplation to action. These principles for effectively using the pros and cons based on an individual's degree of readiness have been replicated with at least 12 different problem behaviors. $^{31}$

Fourth, as in previous studies, ${ }^{27}$ females felt more efficacious than males regarding the use of contraceptives in general and for using condoms-but with secondary partners only. No sex differences were found for condom use efficacy with main partners. In fact, lower levels of confidence were reported for using condoms by both men and women with main partners, suggesting that in important intimate relationships issues such as commitment or fidelity may interfere with condoms being used. These sex differences 
are consistent with earlier studies examining another behavioral skill, assertiveness for contraceptive and condom use. ${ }^{14,25}$ Assessing condom use with the two types of partners continues to reveal striking differences in men's and women's attitudes and behaviors.

Finally, as predicted, perceived self-efficacy was the lowest for individuals in the precontemplation stage. Self-efficacy was shown to increase for those further along in the stages of change. This observation points out that behavioral skill-training strategies, which are the hallmark of many action-oriented interventions, may be appropriate for only a small percentage of the population at risk-those who are ready to adopt and comply with consistent contraceptive and condom use. Information and motivational strategies that will assist individuals to become better prepared for using contraceptives and condoms are needed first if people are to acquire and maintain their recommended use. Motivational interviewing ${ }^{34}$ holds promise as a mechanism for health care providers to employ when assisting individuals to increase their motivation to use methods that prevent pregnancy and STDs. Such motivational strategies have been shown to integrate well within the stages of change model. ${ }^{35}$ These approaches are useful and appropriate for dealing with individuals in all stages of readiness, but are most effective with the early stages of precontemplation, contemplation, and preparation. Individuals in the later stages (i.e., action and maintenance) may need skills training in addition to motivational strategies. ${ }^{35}$

This study was cross-sectional, focusing on college men and women self-reports of sexual behavior. These limitations restrict the generality of the findings, which are correlational in nature and suggest directions for future studies. Further validation of the findings using different populations and a longitudinal design are needed to more closely examine the issues of contraceptive and condom use adoption and maintenance. Finally, cell sizes for each of the stages were small, and only about one third of the sample were male, placing less confidence on the findings that should be considered preliminary.

\section{CONCLUSION}

In general, the available research on contraceptive and condom use adoption and continuation does not create optimism. The high number of reported cases of unplanned pregnancies, STDs, and HIV underscores the urgent need for the development of effective interventions designed to modify high-risk sexual behavior. Clinicians and other health care providers could potentially benefit by using the framework of the Transtheoretical Model of Behavior Change in their efforts to modify high-risk sexual behavior. The model's intervention strategy is to provide programs that match the stage of change people are in, rather than expect them to accept action-oriented programs. By tailoring prevention programs to an individual's stage of change, we can better serve entire populations at risk and not just small segments of targeted groups who are ready to change.

\section{References}

1. Hayes CD: Risking the Future: Adolescent Sexuality, Pregnancy, and Childbearing. Washington, DC, National Academy Press, 1987.

2. Jones EG, Forrest JD, Goldman N, Henshaw SK, Lincoln R, Rosoff JI, Westoff CF, Wulf D: Teenage pregnancy in developed countries: Determinants and policy implications. Fam Plann Perspect 17:53-62, 1985. 
3. Roper WL, Peterson HB, Curran JW: Condoms and HIV/STD prevention: Clarifying the message. Am J Public Health 83:501-503, 1993.

4. Prochaska JO, DiClemente CC: Stages and processes of self-change in smoking: Toward an integrative model of change. J Consult Clin Psychol 5:390-395, 1983.

5. Prochaska JO, DiClemente CC: The Transtheoretical Approach: Crossing the Traditional Boundaries of Therapy. Homewood, IL, Dow Jones/lrwin, 1984.

6. Prochaska JO, DiClemente CC, Norcross JC: In search of how people change. Am Psychol 47:1102-1114, 1992.

7. Chesney MA: Health psychology in the 21st century: Acquired immunodeficiency syndrome as a harbinger of things to come. Health Psychol 12:259-268, 1993.

8. Horn D: A model for the study of personal choice health behavior. Int J Addict 19:179-185, 1976.

9. Brownell KD, Marlatt GA, Lichtenstein E, Wilson GT: Understanding and preventing relapse. Am Psychol 41:765-782, 1986.

10. Prochaska JO, Velicer WF, Rossi JS, Goldstein MG, Marcus BH, Rakowski W, Fiore C, Harlow LL, Redding CA, Rosenbloom D, Rossi SR: Stages of change and decisional balance for twelve problem behaviors. Health Psychol 13:39-46, 1994.

11. Prochaska JO, Redding CA, Harlow LL, Rossi JS, Velicer WF: The transtheoretical model of change and HIV prevention: A review. Health Educ $Q$ in press.

12. Redding CA: Application of the transtheoretical model to safer sex in a cross-sectional sample of university students. Unpublished doctoral dissertation, University of Rhode Island, Kingston, 1993.

13. Grimley DM, Riley GE, Bellis JM, Prochaska JO: Assessing the stages of change and decision-making for contraceptive use for the prevention of pregnancy, sexually transmitted diseases, and acquired immunodeficiency syndrome. Health Educ Q 20:455-470, 1993.

14. Grimley DM, Riley GE, Prochaska JO: Condom use assertion and the stages of change with main and other partners. J Appl Biobehav Res in press.

15. Grimley DM, Riley GE, Prochaska JO: The Stages and the Processes of Change for Condom Use. Unpublished manuscript, 1994.

16. Grimley DM, Riley GE, Prochaska JO, Redding CA, Ruggiero L, Velicer WF, Rossi JS: The Application of the Transtheoretical Model to Contraceptive and Condom Use in High-Risk Women. Atlanta, GA, Centers for Disease Control and Prevention, Contract Grant CSA-92-109, 1992.

17. Prochaska JO, Harlow LL, Redding CA, Snow MG, Rossi JS, Velicer WF: Stages of Change, Self-Efficacy, and Decisional Balance for Condom Use and a High-Risk Sample. Atlanta, GA, Centers for Disease Control and Prevention, Contract Grant 0-415-002, 1990.

18. Velicer WF, DiClemente CC, Prochaska JO, Brandenburg N: A decisional balance measure for predicting smoking cessation. J Pers Soc Psychol 48:1279-1289, 1985.

19. DiClemente CC: Self-efficacy and the addictive behaviors. J Consult Clin Psychol 4:302-315, 1986.

20. Velicer WF, DiClemente CC, Rossi JS, Prochaska JO: Relapse situations and self-efficacy: An integrative model. Addict Behav 15:271-283, 1990.

21. Bandura A: Self-efficacy: Toward a unifying theory of behavior change. Psychol Rev 84:191215, 1982.

22. Bandura A: Social Foundations of Thought and Action: A Social Cognitive Theory. Englewood Cliffs, NJ: Prentice-Hall, 1986.

23. DiClemente CC, Prochaska JO, Fairhurst S, Velicer WF, Velasquez MM, Rossi JS: The processes of smoking cessation: An analysis of precontemplation, contemplation, and preparation stages of change. J Consult Clin Psychol 59:295-304, 1991.

24. Prochaska JO, DiClemente CC: Stages and the processes of self-change in smoking: Toward an integrative model of change. J Consult Clin Psychol 51:390-395, 1983. 
25. Grimley DM: Contraceptive use for the prevention of pregnancy, STDs, and AIDS: A transtheoretical approach. Unpublished doctoral dissertation, Psychology Department, University of Rhode Island, Kingston, 1994.

26. Fishbein M, Douglas JM, Rhodes F, Hananel LD, Napolitano E: Distribution of STD clinic patients along a stages-of-change continuum: Selected sites, 1993. MMWR 42:880-883, 1993.

27. Goldman JA, Harlow LL: Self-perception variables that mediate AIDS-preventive behavior in college students. Health Psychol 12:489-498, 1993.

28. Sacco WP, Rickman RL, Thompson K, Levine B, Reed DL: Gender differences in AIDS-relevant condom attitudes and condom use. AIDS Educ Prev 5:311-326, 1993.

29. Galavotti C, Cabral R, Grimley DM, Prochaska JO, Riley GE: The prevention of HIV in women and infants demonstration projects: Measuring condom and contraceptive behavior among women at high-risk for HIV infection or transmission. (Abstract \#PO-D38-4416) IX International AIDS Conference, Germany, 1993, June.

30. Grimley DM, Riley GE, Velicer WF, Prochaska JO, Galavotti C, Cabral R: Conceptual model testing for contraceptive and condom use. Paper presented at the 101 st annual meeting of the American Psychological Association, Toronto, CA, 1993, August.

31. Prochaska JO: Strong and weak principles for progressing from precontemplation to action based on twelve problem behaviors. Health Psychol 13:47-51, 1994.

32. Zabin LS, Astone NM, Emerson MR: Do adolescents want babies? The relationship between attitudes and behavior. J Res Adolescence 3:67-86, 1993.

33. Byrne D, Kelley K, Fisher WA: Unwanted teenage pregnancies: Incidence, interpretation, and intervention. Appl Preven Psychol 2:101-113, 1993.

34. Miller WR, Rollnick S (eds.): Motivational Interviewing: Preparing People to Change Addictive Behaviors. New York, Guilford Press, 1991.

35. DiClemente CC: Motivational interviewing and the stages of change, in Miller WR, Rollnick S (eds.). Motivational Interviewing: Preparing People to Change Addictive Behaviors. New York, Guilford Press, 1991. 